\title{
INTERDEPENDENCE BETWEEN SOME MAJOR EUROPEAN STOCK MARKETS - A WAVELET LEAD/LAG ANALYSIS
}

\author{
Silvo Dajčman*
}

\begin{abstract}
:
This paper investigates multiscale interdependence between the stock markets of Germany, Austria, France, and the United Kingdom. Wavelet energy additive decomposition was analyzed to investigate which scales capture the most energy (volatility), whereas a wavelet cross-correlation estimator was used to analyze comovement and lead/lag relationship between stock markets' return dynamics on a scale-by-scale basis. The main findings of the paper are as follows. First, major financial market crises had a significant impact on return volatility of investigated stock markets. Among them, the global financial crisis of 2007-2008 had the greatest and the most durable impact. Second, the lowest scale (associated with stock markets' return dynamics over a 2-4 days horizon) and the second lowest scale (associated with stock markets' return dynamics over 4-8 days horizon) MODWT (maximal overlap discrete wavelet transform) decompositions of stock markets' returns captured the greatest share (together about $70-80 \%$ ) of indices' returns volatility. Third, comovement between stock market returns is a scale-dependent phenomenon. Fourth, a strong comovement between stock market returns of Germany, France, and the United Kingdom exists at all scales, while the Austrian stock market is less correlated with the three biggest stock markets in Europe. Fifth, the dynamics of stock market returns seems to be well time-synchronized at daily (raw returns) and the lowest scale (scale ) return decomposition as most of the return innovations are transmitted between stock markets intraday. Sixth, at the highest investigated scale (associated with stock markets' return dynamics over a 64-128 days horizon), significant leads and lags between dynamics of stock markets' returns were detected. The time-synchronization of the stock markets' return dynamics for investments of 64 to 128 days horizon is less perfect than for investments of shorter investment horizons.
\end{abstract}

Keywords: stock markets, wavelet analysis, wavelet cross-correlation, return spillovers

JEL Classification: G15, G11, F36

\section{Introduction}

International stock market linkages are of great importance for financial decisions of international investors. Since the seminal works of Markowitz (1958) and empirical evidence of Grubel (1968), it is recognized, that international diversification reduces total risk of a portfolio. Increased comovement between asset returns can diminish the advantage of internationally diversified investment portfolios (Ling and Dhesi, 2010). Changes in comovement patterns call for an adjustment of portfolios (Savva

* Department of Finance, Faculty of Economics and Business, University of Maribor, Razlagova 14, 2000 Maribor, Slovenia (silvo.dajcman@uni-mb.si). 
and Aslanidis, 2010). Furthermore, if spillovers are found in return series then it is possible to exploit strategy profits which are against the market efficiency criteria (Harris and Pisedtasalasai, 2005).

In existing literature, the following methods are usually used to measure the level of stock market return (or price) comovement and spillovers: (1) correlation coefficients (e.g., Koedijk et al., 2002; Longin and Solnik, 1995) to measure comovement; (2) Vector Autoregressive (VAR) models (Malliaris and Urrutia, 1992; Gilmore and McManus, 2002) to estimate spillover effects between stock markets; (3) cointegration analysis (Gerrits and Yuce, 1999; Patev et al., 2006) to find long-term comovements between stock markets; (4) GARCH models (Tse and Tsui, 2002; Bae et al., 2003; Égert and Kočenda, 2010; Mazin et al., 2010) and regime switching models to model spillovers (Garcia and Tsafack, 2009; Schwender, 2010). A novel, but very promising approach, is wavelet analysis, which can be used to investigate both, stock market comovements and spillovers.

Economic and financial phenomena may exhibit different characteristics on different time scales and wavelet analysis tools enable us to investigate the multiscale features of these phenomena. As wavelets are localized in both time and scale, unlike Fourier analysis, and spectral analysis, they thus provide a convenient and efficient way of representing complex variables or signals (Ramsey, 1999). Moreover, because of the translation and scale properties, nonstationarity in data is not a problem when using wavelets and prefiltering is not needed (Pinho in Madaleno, 2009). Wavelet analysis is suitable for detecting seasonal and cyclical patterns, structural breaks, trend analysis, fractal structures and multiresolution analysis (Crowley, 2005). ${ }^{1}$ Wavelets in finance are primarily used as a signal decomposition tool (e.g. Mallat and Zhang, 1993; Gençay et al., 2001a; Gençay et al., 2003; Gençay et al., 2005; Vuorenmaa, 2006), or a tool to detect interdependence between variables (In and Kim, 2006; In et al., 2008; Kim and In, 2005; Kim and In, 2007).

Wavelet cross-correlation tools can be used to analyze the lead/lag (spillover) relationship between two time series for different time scales. If one time series leads the other, then its realizations may be used to forecast the realizations of the lagging time series. The size and significance of cross-correlation tells if the leading time series has predictive power for the lagging time series. Just as the usual time-domain crosscorrelation is used to determine lead/lag relationships between two time series, the wavelet cross-correlation will provide a lead/lag relationship on a scale-by-scale basis. When two time series are time-aligned, their cross-correlation estimate for lag zero is equal to correlation between the two time series and tells how much they comove. Further, if cross-correlations of the two time series are not significant at non-zero leads/lags, we may say that two time series are well time synchronized. The wavelet cross-correlation has been recently used in different scientific disciplines: in biology (Hudson et al., 2010), physics (Turbelin et al., 2009), medicine (de Trad et al., 2001) and also in economics.

1 Good descriptions of wavelets and their applications can be found in Daubechies (1992), Percival and Walden (2000), Gençay et al. (2002), Mallat (2009). 
There are a few studies using wavelet cross-correlation to investigate spillover effects between financial variables for different time scales. Gallegati (2008) studied the relationship between stock market returns and economic activity. He applied a maximal overlap discrete wavelet transform (MODWT) analysis to study the lead/lag relationship between stock prices and industrial production for different time scales. His results show that stock markets tend to lead the level of economic activity, but only at the highest scales (lowest frequencies), and the leading period increases as the scale increases. Cardinali (2009), by using MODWT lead/lag analysis, found evidence that Eurodollar implied volatilities contain predictive information about realized volatilities. Ranta (2010) applied MODWT cross-correlation tool to study the lead/lag relationship between stock indices DAX, FTSE100, S\&P500, and Nikkei225. Wavelet cross-correlation for the time scales of a day and a week showed a flow (spillover) of volatility from the S\&P500 to other indices. On a one month scale, there was flow of volatility from the European indices, especially from the DAX to the S\&P500, and Nikkei225.

Using MODWT tools, this paper aims to answer four questions: What effect did major financial market crises have on volatilities of stock market returns of Austria, Germany, France and the United Kingdom? Are return comovements and spillovers between stock markets a multiscale (i.e. time-frequency) phenomena? How well are dynamics of different stock market returns time-synchronized at particular time scales? and which stock markets are leading, and thus preceding other stock markets in their return dynamics?

\section{Description of the Maximal Overlap Discrete Wavelet Transform (MODWT)}

\subsection{Wavelet analysis}

Similar to Fourier analysis, wavelet analysis ${ }^{1}$ involves the projection of the original series onto a sequence of basic functions, which are known as wavelets. There are two basic wavelet functions: the father wavelet (called also a scaling function), $\phi$, and the mother wavelet (called also a wavelet function), $\psi$, which can be scaled and translated to form a basis for the Hilbert space $L^{2}(\mathbb{R})$ of square integrable functions.

The father and mother wavelets are defined by the functions:

$$
\begin{gathered}
\phi_{j, k}(t)=2^{-\frac{j}{2}} \phi\left(2^{-j} t-k\right), \\
\psi_{j, k}(t)=2^{-\frac{j}{2}} \psi\left(2^{-j} t-k\right),
\end{gathered}
$$

where $j=1, \ldots J$ is the scaling parameter in a $J$-level decomposition and $k$ is a translation parameter $(j, k \in \mathbb{Z})$. The long term trend of the time series is captured by the father wavelet, which integrates to 1 , while the mother wavelet, which integrates to 0 , describes fluctuations from the trend. The continuous wavelet transform of a square integrable time series $X(t)$ consists of the scaling, $\alpha_{J, k}$, and wavelet coefficients, $\beta_{J, k}$, (Craigmile and Percival, 2002): 
and

$$
\alpha_{J, k}(t)=\int \phi_{J, k}(t) X(t)
$$

$$
\beta_{j, k}(t)=\int \psi_{j, k}(t) X(t)
$$

It is possible to reconstruct from these transform coefficients using:

$$
X(t)=\sum_{k} \alpha_{J, k} \phi_{J, k}(t)+\sum_{k} \beta_{J, k} \psi_{J, k}(t)+\sum_{k} \beta_{J-1, k} \psi_{J-1, k}(t)+\ldots+\sum_{k} \beta_{1, k} \psi_{1, k}(t) .
$$

In practice we observe a time series at finite number of regularly spaced times, so we can make use of a discrete wavelet transform (DWT) ${ }^{2}$ or a maximal overlap discrete wavelet transform (MODWT). The MODWT is a linear filtering operation that transforms a series into coefficients related to variations over a set of scales. It is similar to the discrete wavelet transform, but it gives up the orthogonality property of the DWT to gain other features, that render MODWT more suitable for the aims of our study, as (Percival and Mojfeld, 1997): i) the ability to handle any sample size regardless of whether the series is dyadic (that is of size $2^{J_{0}}$, where $J_{0}$ is a positive integer number), or not; ii) increased resolution at higher scales as the MODWT oversamples the data; iii) translation-invariance, which ensures that MODWT wavelet coefficients do not change if the time series is shifted in a "circular" fashion; iv) the MODWT produces a more asymptotically efficient wavelet variance estimator than the DWT.

\subsection{MODWT wavelet analysis}

Let $^{3} \boldsymbol{X}$ be a $N$ dimensional vector whose elements are the real-valued time series $\left\{X_{t}: \mathrm{t}=0, \ldots, N-1\right\}$, where the sample size $N$ is any positive integer. For any positive integer, $J_{0}$, the level $J_{0}$ MODWT of $\boldsymbol{X}$ is a transform consisting of the $J_{0}+1$ vectors $\widetilde{\boldsymbol{W}}_{1}, \ldots, \widetilde{\boldsymbol{W}}_{J_{0}}$ and $\widetilde{\boldsymbol{V}}_{J_{0}}$, all of which have the dimension $N$. The vector $\widetilde{\boldsymbol{W}}_{J_{1}}$ contains the MODWT wavelet coefficients associated with changes at scale $\tau j=2^{j-1}$ (for $\left.j=1, \ldots, J_{0}\right),{ }^{4}$ while $\widetilde{\boldsymbol{V}}_{J_{0}}$ contains MODWT scaling coefficients associated with averages at scale $\lambda_{J_{0}}=2^{J_{0}}$.

Based upon a definition of MODWT coefficients we can write (Percival and Walden, 2000):

$$
\widetilde{\boldsymbol{W}}_{j}=\widetilde{W}_{j} \boldsymbol{X}
$$

and

$$
\widetilde{\boldsymbol{V}}_{J_{0}}=\widetilde{V}_{J_{0}} \boldsymbol{X}
$$

where $\widetilde{W_{J}}$ and $\widetilde{V}_{J_{0}}$ are $N \times N$ matrices.

2 For a presentation of DWT, please refer to Percival and Walden (2000).

3 Concepts and notations as in Percival and Walden (2000) are used.

4 Percival and Walden (2000) denote scales of MODWT obtained wavelet coefficients with a letter $\tau$ and scales of scaling coefficients with $\lambda$. We use the same notations. 
By definition, the elements of $\widetilde{\boldsymbol{W}_{J_{1}}}$ and $\widetilde{\boldsymbol{V}}_{J_{0}}$ are outputs obtained by filtering $\boldsymbol{X}$, namely:

and

$$
\widetilde{W}_{j, t}=\sum_{l=0}^{L_{j}-1} \tilde{h}_{j, l} X_{t-l \bmod N}
$$

$$
\widetilde{V}_{j, t}=\sum_{(l=0)}^{\left(L_{j}-1\right)} \tilde{g}_{(j, l)} X_{(t-l m o d N)},
$$

for $t=0, \ldots, N-1$, and where $\tilde{h}_{(j, l)}$ and $\tilde{g}_{(j, l)}$ are the $j$ th-level MODWT wavelet and scaling filters defined in terms of the $j$ th-level equivalent wavelet and scaling filters $\left\{h_{j, l}\right\}$ and $\left\{g_{j, l}\right\}$ for a discrete wavelet transform (DWT):

and

$$
\tilde{h}_{j, l}=h_{j, l} / 2^{j / 2}
$$

$$
\tilde{g}_{j, l}=g_{j, l} / 2^{j / 2} .
$$

Each of the MODWT wavelet filters has width $L_{j} \equiv\left(2^{j}-1\right)(L-1)+1$ and can be calculated once basic MODWT wavelet filter $\tilde{h}_{1, l} \equiv \tilde{h}_{l}=h_{l} / \sqrt{2}$ and MODWT scaling filter $\tilde{g}_{1, l} \equiv \tilde{g}_{l}=(-1)^{l+1} \tilde{h}_{L-1-l}$ have been specified.

A DWT filter $\left\{h_{l}: l=0, \ldots, L-1\right\}$ of even width $L$ is called a wavelet filter if

$$
\sum_{l=0}^{L-1} h_{l}=0
$$

and

$$
\sum_{l=0}^{L-1} g_{l} g_{l+2 n}=\left\{\begin{array}{l}
1, \text { if } n=0 \\
0, \text { if } n \text { is nonzero integer. }
\end{array}\right.
$$

A DWT scaling filter is defined in terms of the wavelet filter

$$
g_{l} \equiv(-1)^{l+1} h_{L-1-l}
$$

and satisfies conditions

1)

$$
\sum_{l} g_{l}=\sqrt{2}
$$

$$
\sum_{l=0}^{L-1} g_{l} g_{l+2 n}=\left\{\begin{array}{l}
1, \text { if } n=0 \\
0, \text { if } n \text { is nonzero integer. }
\end{array}\right.
$$

The MODWT treats the series as if it were periodic, whereby the unobserved samples of the real-valued time series $X_{-1}, X_{-2}, \ldots X_{-N}$ are assigned the observed values at $X_{N-1}$, $X_{N-2}, \ldots X_{0}$. The MODWT coefficients are thus given by:

$$
\widetilde{W}_{j, t}=\sum_{l=0}^{N-1} \tilde{h}_{j, l}^{\circ} X_{t-l \bmod N}
$$

and 


$$
\widetilde{V}_{j, t}=\sum_{l=0}^{N-1} \tilde{g}_{j, l}^{\circ} X_{t-l \bmod N}
$$

for $t=0, \ldots, N-1 ; \tilde{h}_{j, l}^{\circ}$; and $\tilde{g}_{j, l}^{\circ}$ are periodization of $\tilde{h}_{j, l}$ and $\tilde{g}_{j, l}$ to circular filters of length $N$.

This periodic extension of the time series is known as analyzing $\left\{X_{l}\right\}$ using "circular boundary condition" (Percival and Walden, 2000; Cornish et al., 2006). There are $L j=1$ wavelet and scaling coefficients that are influenced by the extension ("the boundary coefficients"). Since $L j$ increases with $j$, the number of boundary coefficients increases with scale. Exclusion of boundary coefficients in the wavelet variance, wavelet correlation and covariance provides unbiased estimates (Cornish et al., 2006).

\subsection{Wavelet variance and wavelet correlation}

One of the important uses of the MODWT is to decompose the sample variance of a time series on a scale-by-scale basis. Since the MODWT is energy conserving (Percival and Mojfeld, 1997)

$$
\left\|\boldsymbol{X}^{2}\right\|=\sum_{j=1}^{J_{0}}\left\|\widetilde{\boldsymbol{W}}_{j}\right\|^{2}+\left\|\widetilde{\boldsymbol{V}}_{j_{0}}\right\|^{2},
$$

a scale-dependent analysis of variance from the wavelet and scaling coefficients can be derived (Cornish et al., 2006):

$$
\hat{v}_{X}^{2}=\left\|\boldsymbol{X}^{2}\right\|-\bar{X}^{2}=\frac{1}{N} \sum_{j=1}^{J_{0}}\left\|\widetilde{\boldsymbol{W}}_{j}\right\|^{2}+\frac{1}{N}\left\|\widetilde{\boldsymbol{V}}_{j_{0}}\right\|^{2}-\bar{X}^{2} .
$$

Wavelet variance is defined for stationary and nonstationary processes with stationary backward differences (Percival and Walden, 2000). Let $\left\{X_{t}: t=\ldots,-1,0,1, \ldots\right\}$ be a discrete parameter real-valued stochastic process whose $d$ th-order diferencing ( $d$ may take any nonnegative integer values) gives a stationary process

$$
Y_{t} \equiv(1-B)^{d} X_{t} \equiv \sum_{k=0}^{d}\left(\begin{array}{l}
d \\
k
\end{array}\right)(-1)^{k} X_{t-k},
$$

with spectral density function (SDF) $S_{Y}(\cdot)$ and mean $\mu_{Y}$ (which may not be zero). Let $S_{X}(\cdot)$ represent the SDF for $\left\{X_{t}\right\}$, for which $S_{X}(f)=S_{Y}(f) / D^{d}(f)$, where $\mathrm{D}(f) \equiv 4 \sin ^{2}(\pi f)$ (if $\left\{X_{t}\right\}$ is a nonstationary process, then this relationship between $S_{X}(\cdot)$ and $S_{Y}(\cdot)$ represents definition for $\left.S_{X}(\cdot)\right)$. Filtering $\left\{X_{t}\right\}$ with a MODWT Daubechies wavelet filter $\left\{\tilde{h}_{j . l}\right\}$ of width $L \geq 2 d,{ }^{5}$ a stationary process of $j$ th-level MODWT wavelet is obtained:

5 That means the filter size must be at least the double size of the order of differencing the time series. For stationary processes any filter width is appropriate. 


$$
\bar{W}_{j, t} \equiv \sum_{l=0}^{L_{j}-1} \tilde{h}_{j . l} X_{t-l}, t=\ldots,-1,0,1, \ldots,
$$

where $\bar{W}_{j, t}$ is a stochastic process obtained by filtering $\left\{X_{t}\right\}$ with the MODWT wavelet filter $\left\{\tilde{h}_{j . l}\right\}^{6}$ and $L_{j} \equiv\left(2^{j}-1\right)(L-1)+1$.

Let us suppose that we are given a time series, which is realization of one segment (segment with values $X_{0}, \ldots, \mathrm{X}_{N-1}$ ) of the process $\left\{X_{t}\right\}$. Under condition $M_{j} \equiv N-L_{j}+1>0$ (i.e. by considering only the non-boundary wavelet coefficients, obtained by filtering stationary time series with MODWT) and that either $L>2 d$ or $\mu_{x}=0$ (realization of either of these two conditions implies $E\left\{\bar{W}_{j, t}\right\}=0$ and therefore $\left.v_{X}^{2}\left(\tau_{j}\right)=E\left\{\bar{W}_{j, t}^{2}\right\}^{7}\right)$, an unbiased estimator of wavelet variance of scale $\tau_{j}\left(v_{X}^{2}\left(\tau_{j}\right)\right)$ is given by (Percival and Walden, 2000):

$$
\hat{v}_{X}^{2}\left(\tau_{j}\right)=\frac{1}{M_{j}} \sum_{t=L_{j}-1}^{N-1} \widetilde{W}_{j, t}^{2},
$$

where $\left\{\widetilde{W}_{j, t}\right\}$ are the $j$ th-level MODWT wavelet coefficients for time series $\left(\widetilde{W}_{j, t} \equiv \sum_{l=0}^{L_{j}-1} \tilde{h}_{j . l} X_{t-l \text { modN }}, t=0,1, \ldots, N-1\right)$.

It is possible to prove that the asymptotic distribution of $\hat{v}_{X}^{2}\left(\tau_{j}\right)$ is Gaussian, a result that allows the formulation of confidence intervals for the estimate (Percival, 1995; Serroukh et al., 2000).

Given two stationary processes $\left\{X_{t}\right\}$ and $\left\{Y_{t}\right\}$, whose $j$ th-level MODWT wavelet coefficients are $\left\{\bar{W}_{X, j, t}\right\}$ and $\left\{\bar{W}_{Y, j, t}\right\}$, an unbiased covariance estimator $\hat{v}_{X Y}\left(\tau_{j}\right)$ is given by (Percival, 1995):

$$
\hat{v}_{X, Y}\left(\tau_{j}\right)=\frac{1}{M_{j}} \sum_{t=L_{j}-1}^{N-1} \widetilde{W}_{j, t}^{(X)} \widetilde{W}_{j, t}^{(Y)}=\operatorname{cov}\left\{\bar{W}_{X, j, t}, \bar{W}_{Y, j, t}\right\},
$$

where $M_{j} \equiv N-L_{j}+1>0$ is the number of non-boundary coefficients at the $j$ th-level.

The MODWT correlation estimator for scale $\tau_{j}$ is obtained by making use of the wavelet covariance and the square root of wavelet variances:

$$
\hat{\rho}_{X, Y}\left(\tau_{j}\right)=\frac{\hat{v}_{X, Y}\left(\tau_{j}\right)}{\hat{v}_{X}\left(\tau_{j}\right) \hat{v}_{\mathrm{Y}}\left(\tau_{j}\right)},
$$

where $\left|\hat{\rho}_{X Y}\left(\tau_{j}\right)\right| \leq 1$. The wavelet correlation is analogous to its Fourier equivalent, the complex coherency (Gençay et al., 2002).

Calculation of confidence intervals is based on Percival (1995) and Percival and Walden (2000). The random interval

$6 \quad \bar{W}_{j, t}$ is obtained by filtering an infinite sequence, while $\widetilde{W}_{j, t}$ is obtained by filtering a finite sequence (Percival and Walden, 2000).

$7 \quad$ In this case we obtain $v_{X}^{2}\left(\tau_{j}\right)=\operatorname{var}\left\{\bar{W}_{j, t}\right\}=E\left\{\left(\bar{W}_{j, t}-E\left\{\bar{W}_{j, t}\right\}\right)^{2}\right\}=E\left\{\bar{W}_{j, t}^{2}\right\}$ 


$$
\left[\tanh \left\{\mathrm{h}\left[\rho_{X Y}\left(\tau_{j}\right)\right]-\frac{\Phi^{-1}(1-\mathrm{p})}{\sqrt{\mathrm{N}_{\mathrm{j}}-3}}\right\}, \tanh \left\{\mathrm{h}\left[\rho_{X Y}\left(\tau_{j}\right)\right]+\frac{\Phi^{-1}(1-\mathrm{p})}{\sqrt{\mathrm{N}_{\mathrm{j}}-3}}\right\}\right]
$$

captures the true wavelet correlation and provides an approximate $100(1-2 p) \%$ confidence interval. Function $h(p)=\tanh ^{-1} \hat{\rho}$ defines the Fisher's z-transformation. $N_{j}$ is the number of wavelet coefficients obtained by jth-level of DWT and not by the MODWT transformation. This is because the Fisher's z-transformation assumes uncorrelated observations and the DWT is known to approximately decorrelate a wide range of power-law processes (Ranta, 2010).

\subsection{Wavelet cross-correlation}

Cross-correlation is a method of estimating the degree to which two time series are correlated. We can shift one time series (either lag [ $\pi$ is then negative] or lead [ $\pi$ is then positive]) and then calculate the correlation between the two time series. Crosscorrelation analysis helps identify which time series return innovations are leading the other time series return innovations, with the latter time series characterized as lagging). The size and significance of cross-correlation estimates reveal if the leading time series has predictive power for the lagging time series. Just as the usual time-domain crosscorrelation is used to determine lead/lag relationships between two time series, the wavelet cross-correlation will provide a lead/lag relationship on a scale-by-scale basis.

The MODWT cross-correlation for scale $\tau_{j}$ at lag $\pi$, is defined as (Guttorp et al., 1999):

$$
\rho_{\pi, X Y}\left(\tau_{j}\right)=\frac{\operatorname{cov}\left\{\bar{W}_{j, t}^{(X)}, \bar{W}_{j, t+\pi}^{(Y)}\right\}}{\left(\operatorname{var}\left\{\bar{W}_{j, t}^{(X)}\right\} \operatorname{var}\left\{\bar{W}_{j, t+\pi}^{(Y)}\right\}\right)^{\frac{1}{2}}},
$$

where $\bar{W}_{j, t}^{(X)}$ are the jth-level MODWT wavelet coefficients of time series $\left\{X_{t}\right\}$, at time $t$, and $\bar{W}_{j, t+\pi}^{(Y)}$ are the $j$ th-level MODWT wavelet coefficients of time series $\left\{Y_{t}\right\}$ lagged for $\pi$ time units.

Wavelet cross-correlation takes values $-1 \leq \hat{\rho}_{\pi, X Y}\left(\tau_{j}\right) \leq 1$, for all $\tau$ and $j$. This can be shown using Cauchy-Schwartz inequality. ${ }^{8}$

\section{Empirical Results}

\subsection{Data description}

Returns of stock indices are calculated as differences of logarithmic daily closing prices:

$$
\ln \left(P_{t}\right)-\ln \left(P_{t}-1\right)
$$

where $P$ is an index price.

$8 \quad$ Proof can be found in Pecival (1995). 
The following stock market indices are considered: CAC40 (for France), the DAX (for Germany), the FTSE100 (for the United Kingdom) and the ATX (for Austria). The first day of observation is April 1, 1997, and the last day is May 12, 2010. Days with no trading on any of the observed stock markets were left out. The total number of observations amounts to 3,060 days. The data source for each index value was Yahoo! Finance.

Table 1 presents descriptive statistics of the data. The Jarque-Bera test rejects the hypothesis of a normal distribution of the investigated return time series; all indices' returns are asymmetrically distributed around the sample mean; kurtosis is greater than with normally distributed time series. Such skewness and leptokusis are common features in asset return distributions (Henry, 2002).

Table 1

Descriptive Statistics for Stock Index Return Time Series

\begin{tabular}{|l|c|c|c|c|c|c|c|}
\hline & Min & Max & Mean & $\begin{array}{c}\text { Std. } \\
\text { deviation }\end{array}$ & Skewness & Kurtosis & $\begin{array}{c}\text { Jacque-Bera } \\
\text { statistics }\end{array}$ \\
\hline ATX & -0.1637 & 0.1304 & 0.0002515 & 0.01558 & -0.40 & 14.91 & $18,153.48^{* * *}$ \\
\hline CAC40 & -0.0947 & 0.1059 & 0.0001206 & 0.01628 & 0.09 & 7.83 & $2,982.52^{* \star *}$ \\
\hline DAX & -0.0850 & 0.1080 & 0.0002071 & 0.01756 & -0.06 & 6.58 & $1,635.47^{* \star *}$ \\
\hline FTSE100 & -0.0927 & 0.1079 & 0.0000774 & 0.01361 & 0.09 & 9.30 & $5,069.61^{* * *}$ \\
\hline
\end{tabular}

Note: Regarding the Jarque-Bera test: the null hypothesis is that the sample data come from a normal distribution with unknown mean and variance, against the alternative that it does not come from a normal distribution. JacqueBera statistics: ${ }^{* * *}$ indicates that the null hypothesis (of normal distribution) is rejected at the $1 \%$ significance, ** indicates that the null hypothesis is rejected at the $5 \%$ significance and * that the null hypothesis is rejected at the $10 \%$ significance level.

In Figure 1, we plot the return series of the stock indices. Major financial market downturns in the period April 1998 to May 2010 are denoted on the vertical axis, including the Russian financial crisis, the dot-com financial crisis, the September 11 attacks on the World Trade Center (WTC) (which also had an impact on financial markets), the internet companies bubble burst of July 2002, the Middle East financial market crisis of 2006, and the global financial crisis of 2007-2008. Notably, all of these events had some impact on the volatility of the investigated stock market returns; however, impacts were not uniform. For instance, we notice that dot-com financial crisis, the September 11 attacks and the internet companies bubble burst did not particularly increase volatility of the ATX returns, whereas they had a more pronounced effect on the volatility of other stock market returns. Next, the global financial crisis of 2007-2008 caused the greatest increase in volatilities of stock indices returns. Some financial market downturns had a longer lasting effect on returns volatilities than the others. Two financial market crises stand out for the durability of their effect on increased volatilities are internet companies bubble burst of 2002 and the global financial crisis of 2007-2008. 
Figure 1

Returns of Stock Indices in the Period April 1, 1997 to May 12, 2010
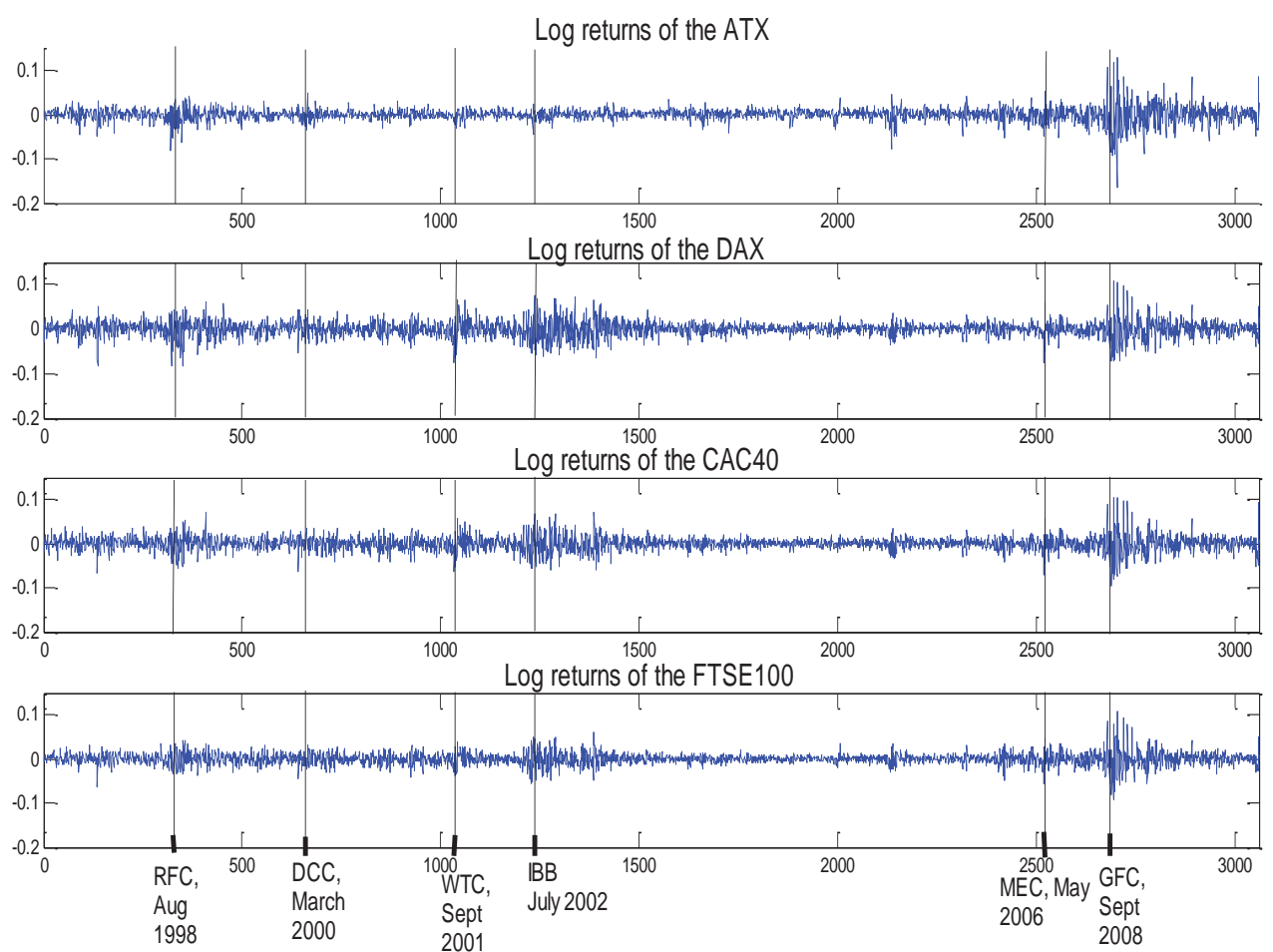

Notes: On the time axis, the financial crises are denoted as RFC = the Russian financial crisis (outbreak on August 13, 1998), DCC = the dot-com crisis (the date is taken when the S\&P500 peaked around March 24, 2000, just before the dot-com crisis began), WTC = attack on the WTC in New York (September 11, 2001), IBB = the internet companies bubble burst (the start of July 2002 is denoted in the figure), MEC = the middle East financial markets crash (the start of May 2006 is denoted), GFC = the global financial crisis (September 16, 2008, when Lehman Brother collapsed is denoted).

To test the stationarity of stock indices' returns, augmented Dickey-Fuller (ADF) test, Phillips-Perron (PP) and Kwiatkowski-Phillips-Schmidt-Shin (KPSS) tests were applied. Test results are presented in Table 2.

Because the trend was not found to be statistically significant for either of the stationarity tests, the models with only a constant were given advantage. The KPSS model results do not reject the null hypothesis of stationary process for any of stock indices' returns whereas the null hypotheses of unit root were rejected for the PP and ADF tests for all stock indices. On the basis of the stationarity tests we conclude that all time series of indices' returns are stationary. 
Table 2

Results of the Stationarity Tests

\begin{tabular}{|l|c|c|c|c|c|c|}
\hline & $\begin{array}{c}\text { KPPS test } \\
\text { (a constant } \\
\text { + trend) }\end{array}$ & $\begin{array}{c}\text { KPSS test } \\
\text { (a constant) }\end{array}$ & $\begin{array}{c}\text { PP test } \\
\text { (a constant } \\
\text { + trend) }\end{array}$ & $\begin{array}{c}\text { PP test } \\
\text { (a constant) }\end{array}$ & $\begin{array}{c}\text { ADF test } \\
\text { (a constant + } \\
\text { trend) }\end{array}$ & $\begin{array}{c}\text { ADF test } \\
\text { (a constant) }\end{array}$ \\
\hline ATX & $\begin{array}{c}0.186^{* *} \\
(12)\end{array}$ & $\begin{array}{c}0.191 \\
(13)\end{array}$ & $\begin{array}{c}-53.586^{* * *} \\
(15)\end{array}$ & $\begin{array}{c}-53.594^{* * *} \\
(15)\end{array}$ & $\begin{array}{c}-40.604^{* *} \\
(\mathrm{~L}=1)\end{array}$ & $\begin{array}{c}-40.608^{* * *} \\
(\mathrm{~L}=1)\end{array}$ \\
\hline CAC40 & $\begin{array}{c}0.110 \\
(15)\end{array}$ & $\begin{array}{c}0.250 \\
(15)\end{array}$ & $\begin{array}{c}-57.840^{* * *} \\
(14)\end{array}$ & $\begin{array}{c}-57.787^{* * *} \\
(14)\end{array}$ & $\begin{array}{c}-36.142^{* * *} \\
(\mathrm{~L}=2)\end{array}$ & $\begin{array}{c}-36.108^{* * *} \\
(\mathrm{~L}=2)\end{array}$ \\
\hline DAX & $\begin{array}{c}0.099 \\
(1)\end{array}$ & $\begin{array}{c}0.105 \\
(1)\end{array}$ & $\begin{array}{c}-57.805^{* * *} \\
(3)\end{array}$ & $\begin{array}{c}-57.812^{* * *} \\
(3)\end{array}$ & $\begin{array}{c}-57.692^{* * *} \\
(\mathrm{~L}=0))\end{array}$ & $\begin{array}{c}-57.698^{* * *} \\
(\mathrm{~L}=0)\end{array}$ \\
\hline FTSE100 & $\begin{array}{c}0.089 \\
(9)\end{array}$ & 0.101 & $-58.284^{* * *}$ & $-58.287^{* * *}$ & $-29.112^{* * *}$ & $-29.111^{* * *}$ \\
$(9)$ & $(7)$ & $(7)$ & $(\mathrm{L}=3)$ & $(\mathrm{L}=3)$ \\
\hline
\end{tabular}

Notes: The KPSS and PP tests were performed for two models: for a model with a constant and for a model with a constant plus trend. Bartlet Kernel estimation method was used with Newey-West automatic bandwidth selection. Optimal bandwidth is indicated in parenthesis under the statistics. For ADF test, two models were applied: a model with a constant and a model with a constant plus trend. The number of lags ( $L$ ) included in the ADF test were selected by SIC criteria (30 was a maximum lag) and are indicated in the parentheses. Exceeded critical values for rejection of the null hypothesis are marked by ${ }^{* * *}$ for a $1 \%$ significance level, by ** for a $5 \%$ significance level and by ${ }^{*}$ for a $10 \%$ significance level.

\subsection{Lead/lag relationships between the returns of stock indices}

MODWT transformations of the indices' return series were performed by using a Daubechies least asymmetric filter with a wavelet filter length of 8 (LA8). This is a common wavelet filter used in empirical studies on financial market interdependencies (Gençay et al., 2001b; Gallegati, 2005; Ranta, 2010). The maximum level of MODWT is $6\left(J_{0}=6\right)$ to achieve an optimal balance between sample size and the length of the filter. Scale $\tau_{1}$ (or scale 1 , as $\tau_{1}=2^{1-1}=1$ ) measures the dynamics of returns over 2 to 4 days ; scale $\tau_{2}$ (scale 2, as $\tau_{2}=2^{2-1}=2$ ) over 4 to 8 days; scale $\tau_{3}$ (scale 4 , as $\tau_{3}=2^{3-1}=4$ ) over 8 to 16 days; scale $\tau_{4}$ (scale $8, \tau_{4}=2^{4-1}=8$ ) over 16 to 32 days; scale $\tau_{5}$ (or scale 16) over 32 to 64 days; and scale $\tau_{6}$ (or scale 32 ) over 64 to 128 days.

To obtain unbiased estimates of cross-correlation, only non-boundary wavelet coefficients were considered. There are 2,619 MODWT wavelet coefficients not affected by boundary condition. ${ }^{10}$ A major drawback of taking a higher maximum number of levels in the MODWT decomposition would be losing sample size. Because we also wanted to include the period after the beginning of the global financial crisis (When Lehman Brother collapsed on September 16, 2008, it caused a global financial market panic; this is taken as the start of the global financial crisis), we decided not to take greater than 6 .

9 The $j$ th-level MODWT coefficients are associated with the frequencies in the interval $\left[\frac{1}{2^{j+1}} \frac{1}{2^{j}}\right]$, i.e. with dynamics or oscillations in the period of $2^{j}$ to $2^{j+1}$ days. See, for example, Gençay et al. (2002, 2003), Lee (2004), Fernandez (2004), or Percival and Walden (2000).

$10 N-L_{j}+1=3060-442+1$, where $L_{j}=\left(2^{6}-1\right)(8-1)+1$ is a width of a wavelet filter. The first 220 observations in each time series are exclued (with time indices $t=0, \ldots L_{j}-2$ ), and the last 221 (with indices $t=N-L_{j}+1, \ldots, N-1$ ). 
We first perform a wavelet variance decomposition analysis (Figure 2) to illustrate that most of volatility in stock indices' return series is captured by lower level MODWT wavelet coefficients (i.e., level $1(j=1)$ MODWT wavelet coefficients, associated with return dynamics over 2 to 4 days and level $2(j=2)$ MODWT wavelet coefficients associated with return dynamics over 4 to 8 days).

Figure 2

Wavelet Variance of Stock Indices' Returns for Different Level of MODWT
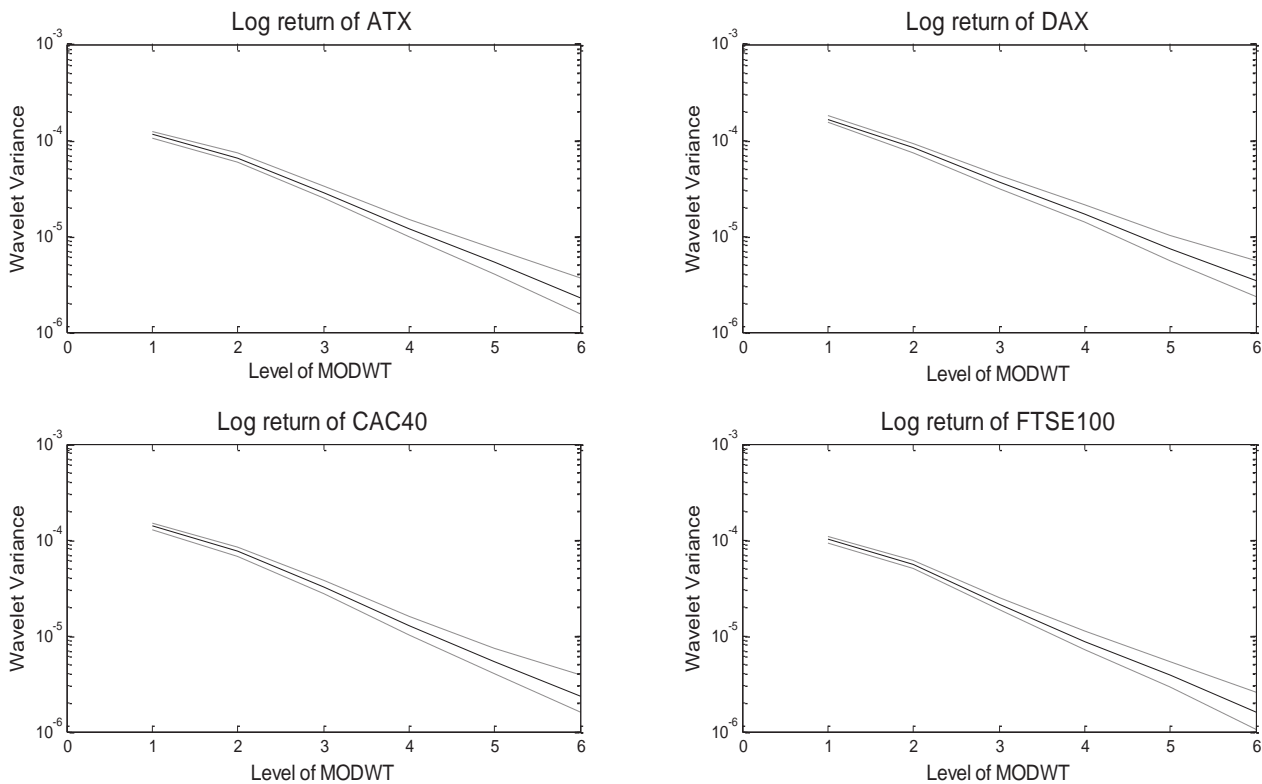

Note: Estimates of wavelet variance for different levels of MODWT wavelet coefficients are drawn with a full line. The $95 \%$ confidence intervals around the wavelet variance estimates are drawn with a dotted line.

Table 3 shows the proportions (in percentages) of the energy of the return series accounted by wavelet coefficients of particular wavelet scales.

Table 3

A Scale-based Energy Decomposition of Stock Indices' Returns (the contribution, in \%, of the jth-wavelet scale energy to the total energy of the signal)

\begin{tabular}{|l|c|c|c|c|c|c|c|c|}
\hline & $\boldsymbol{W}_{\mathbf{1}}$ & $\boldsymbol{W}_{\mathbf{2}}$ & $\boldsymbol{W}_{\mathbf{3}}$ & $\boldsymbol{W}_{\mathbf{4}}$ & $\boldsymbol{W}_{\mathbf{5}}$ & $\boldsymbol{W}_{\mathbf{6}}$ & $\boldsymbol{V}_{\mathbf{6}}$ & Total \\
\hline ATX & 49.5 & 28.2 & 12.3 & 5.2 & 2.3 & 1.0 & 1.5 & 100 \\
\hline DAX & 52.4 & 26.2 & 11.4 & 5.3 & 2.3 & 1.1 & 1.4 & 100 \\
\hline CAC40 & 51.4 & 28.0 & 11.9 & 4.7 & 2.0 & 0.9 & 1.2 & 100 \\
\hline FTSE100 & 52.2 & 28.5 & 11.1 & 4.5 & 2.0 & 0.8 & 0.7 & 100 \\
\hline
\end{tabular}

Note: $W_{j}(j=1, \ldots, 6)$ are MODWT wavelet coefficients at scale $j$, and $V_{6}$ are MODWT scaling coefficients. 
We can observe that high-frequency (low-scale) MODWT coefficients represent more energy (for example, the level 1 MODWT wavelet coefficients, representing shortterm fluctuations due to a shock occurring within a day or two, capture 49.5 to $52.2 \%$ of the total energy of the stock indices' returns) than lower frequency (higher-scale) coefficients (for example, level 6 MODWT wavelet coefficients capture only 0.8 to $1.1 \%$ of the total energy of stock indices' returns $)^{11}$. According to Lee (2004) and Fernandez (2005), a finding such as this indicates that movements in stock returns are mainly caused by short-term fluctuations. This is reasonable, as the longer the investors' investment horizon in stock markets (for example, institutional investors or individuals with longer time horizons), the less rapid their adjustment to shocks. This is in contrast, for example, with daily traders, who adjust their investments more rapidly (intraday) to shocks in stock markets.

Next, we explore cross-correlation between pairs of stock market indices' returns by calculating and then plotting the cross-correlation function for 50 time units of leads/ lags $(\pi=-50,-49, \ldots, 0, \ldots 49,50)$. We thus calculate the cross-correlation between two stock market returns time series first by lagging the second time series by 50 time units. Then, we sequentially repeat the calculation of the cross-correlation for other time shifts (from the lags of 49 time units to the leads of 50 time units). Wavelet crosscorrelations calculated for two indices' return time series that are time-aligned equals the wavelet correlation coefficient. If no correlation coefficient at the leads (or the lags; $\pi \neq 0$ ) of one time series is statistically significantly different than zero, then no time series is leading (or lagging) the other time series. If there are significant crosscorrelation estimates at the leads and lags, then one time series is leading or lagging the other (meaning that the second one is lagging the first). Zero-lag cross-correlation estimates measure comovements (the contemporaneous relationship) between the stock indices returns, whereas non-zero cross-correlation estimates measure the lead-lag (spillover) relationship between the two time series. Due to space considerations, cross-correlations were analyzed for the raw returns only (i.e., untransformed), scale $\tau_{1}$, scale $\tau_{1}$, and scale $\tau_{6}$ MODWT transformed return series.

Wavelet correlation analysis reveals the comovement between stock market returns at different time scales; results are presented in Figure 3. Notably, the estimated wavelet correlation changes with the time scale, suggesting that the return comovement between stock markets is a multiscale phenomenon. The strength of comovement changes more for some stock market pairs (DAX and CAC40), than for others (for example, between CAC40 and FTSE100). The highest correlation between indices' returns is normally achieved at scale 4 (an exception is the ATX correlation with CAC40 and with

11 Lee (2004) and Fernandez (2005) also studied the energy decomposition of stock indices returns. Lee (2004) found that scale 1 and 2 together captured about $70 \%$ of the energy for Korean stock market indices and about $80 \%$ for U.S. stock market indices. Fernandez (2005), analyzing more stock indices (of G7 countries, emerging Asia, Western Europe, Eastern Europe, and the Middle East for the period from 1990 to 2002), found that the first and second scale together captured at least $60 \%$ of the indices' returns volatility. 
FTSE100) ${ }^{12}$ indicating diversification benefits are the smallest for investments with horizons corresponding to scale $\tau_{4}$. Our results support recent findings in the empirical literature (Ranta, 2010; Zhou, 2011), although these studies examined other time periods and stock markets. To achieve diversification benefits, international investors should therefore investigate comovement in invested stock markets for time scales that correspond with their investment horizons. One may also note a strong comovement between stock market returns of Germany, France, and the United Kingdom at all scales, while the Austrian stock market comoves less with the other three investigated stock markets in Europe.

Figure 3

\section{Correlation of Stock Indices' Returns at Different Time Scales}
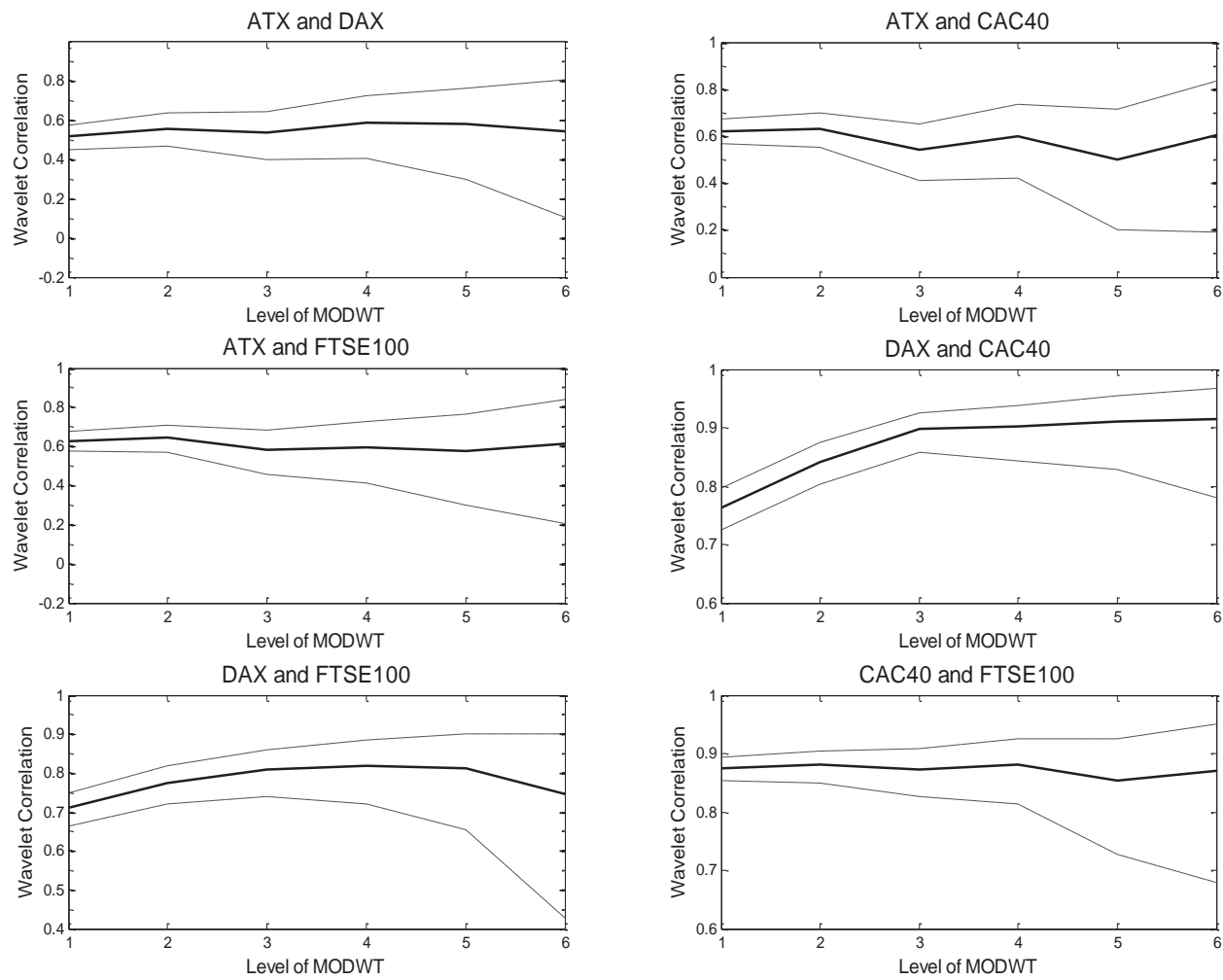

Note: Estimates of correlation between jh-level of MODWT wavelet coefficients are drawn with a full line. The $95 \%$ confidence intervals (calculated by equation (17)) around the wavelet correlation estimates are drawn with dotted line.

12 The finding that comovement between the stock markets often increases as the investment horizon (time scale) is prolonged has a theoretical explanation. At shorter scales, links between the markets are influenced, to a great extent, by sporadic events, market sentiments, and psychological factors that can cause short-term changes in market behavior (Malkiel, 2003; Zhou, 2011). In the long run (higher scales), as Boudoukh et al. (2008) and Zhou (2011) argued, market returns become more predictable as the macro variables exert more predictable influence on the stock market links and cause the correlation to increase. Recent empirical findings from the stock market seem to confirm this (e.g., Ranta, 2010; Zhou, 2011). 
The results of the lead/lag analysis of indices' return series are illustrated in Figures 4 through $9^{13}$.

\section{Figure 4}

\section{Cross-correlation between the Return Series of ATX and DAX}
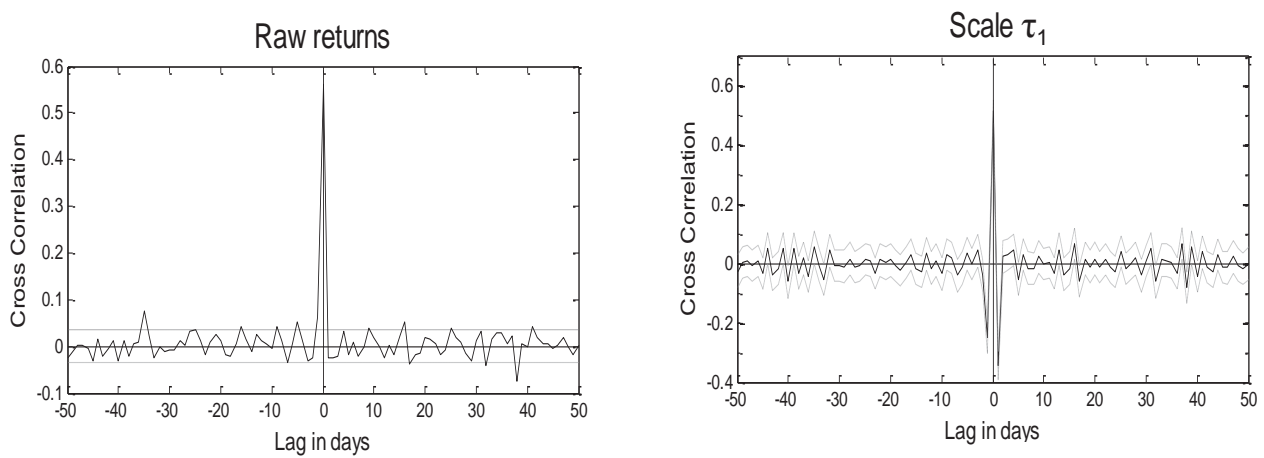

Scale $\tau_{4}$
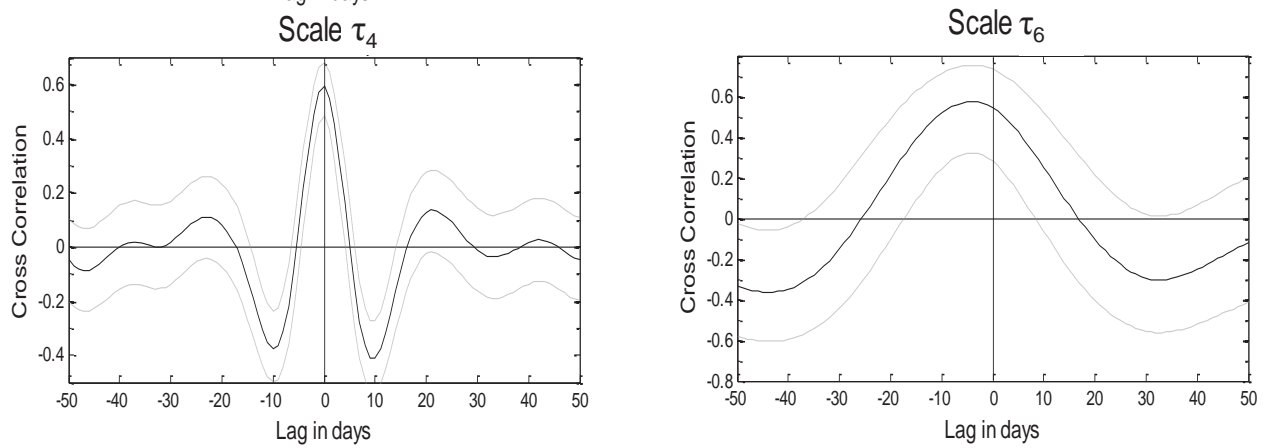

Notes: The cross-correlation is calculated by shifting the second index in the pair (in this case DAX). The 95\% confidence intervals are drawn with a dotted line. For the raw return series the $95 \%$ confidence interval that the crosscorrelation between the two time series is zero is drawn and is calculated using Matlab's built-in cross-correlation function. For the wavelet cross-correlation the 95\% confidence intervals around the cross-correlation estimate are drawn based on the equation (17).

13 When calculating and then graphically presenting the cross-correlation estimates between two time series of stock indices returns, we are shifting the time series of the second stock index in the individual stock indices pairs. For example, in Figure 3, the time series of DAX returns is time shifted. 


\section{Figure 5}

\section{Cross-correlation between the Return Series of ATX and CAC40}
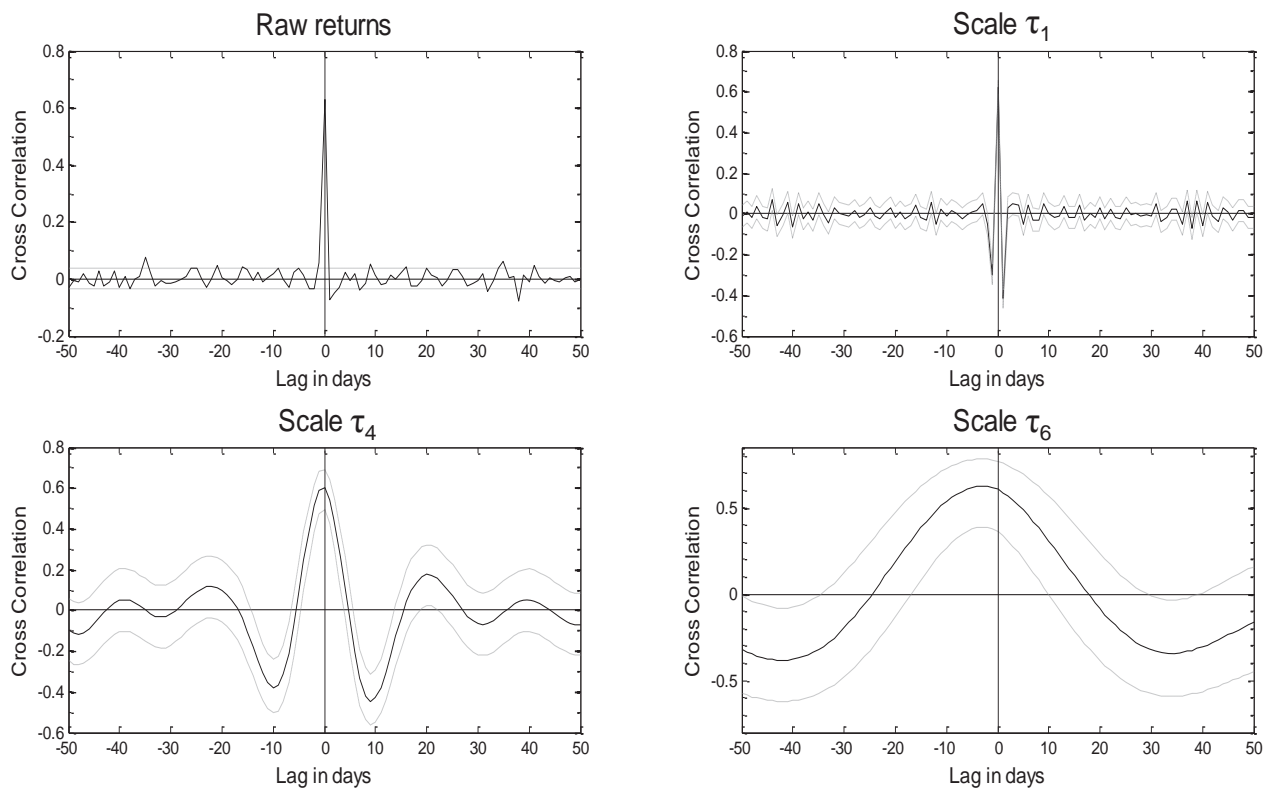

Notes: See notes for Figure 4.

Figure 6

Cross-correlation between the Return Series of ATX and FTSE100
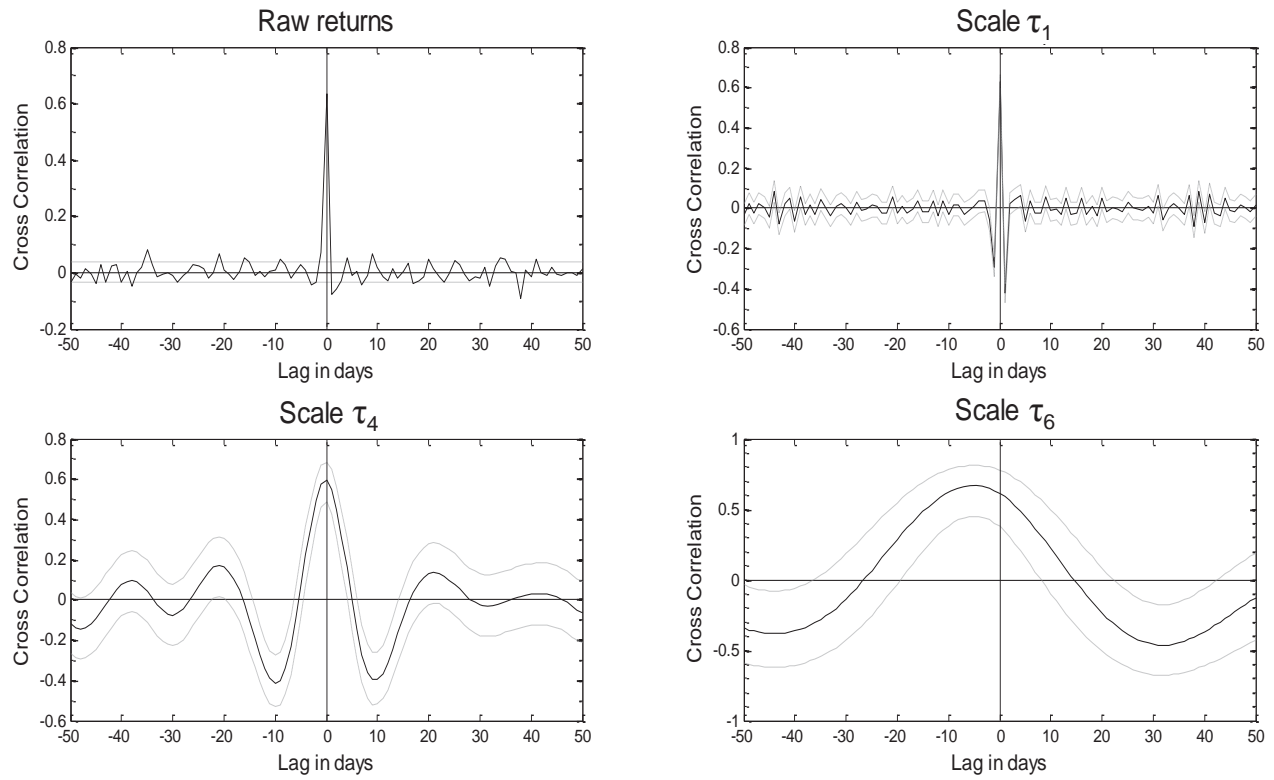

Notes: See notes for Figure 4. 
Figure 7

Cross-correlation between the Return Series of DAX and CAC40
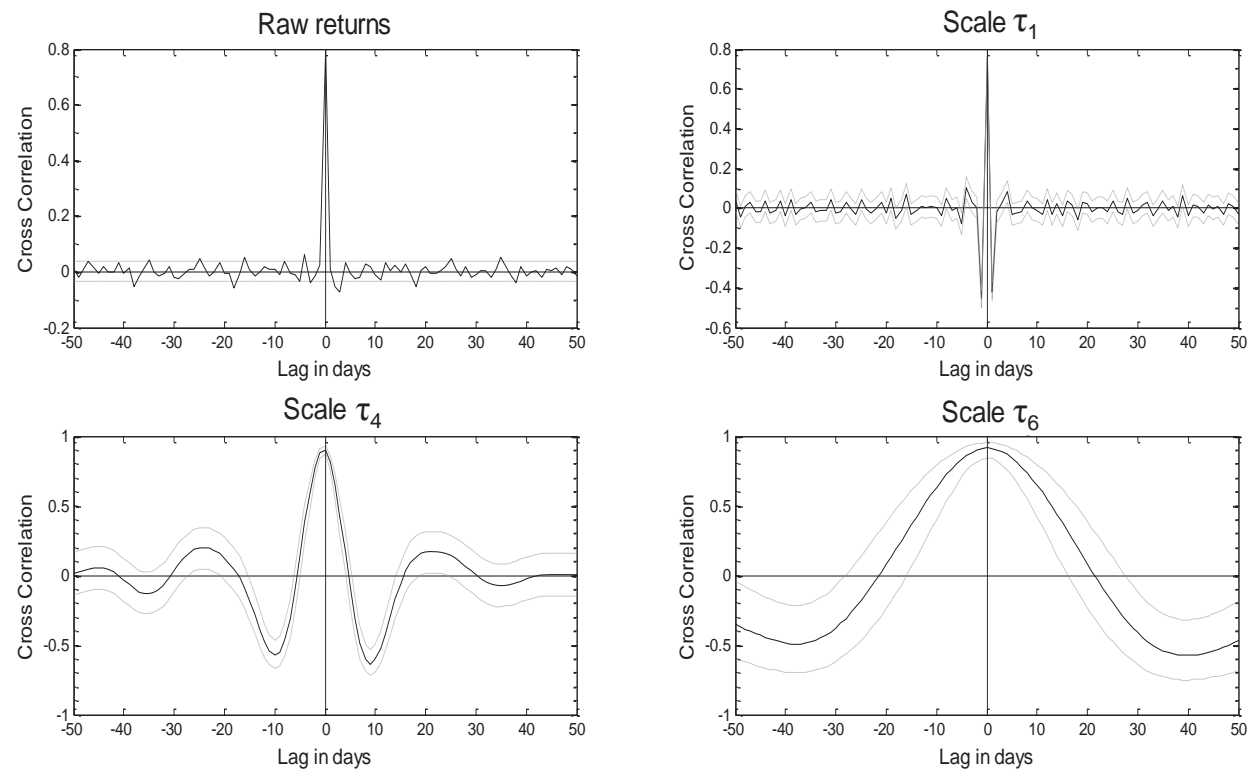

Notes: See notes for Figure 4.

Figure 8

Cross-correlation between the Return Series of DAX and FTSE100
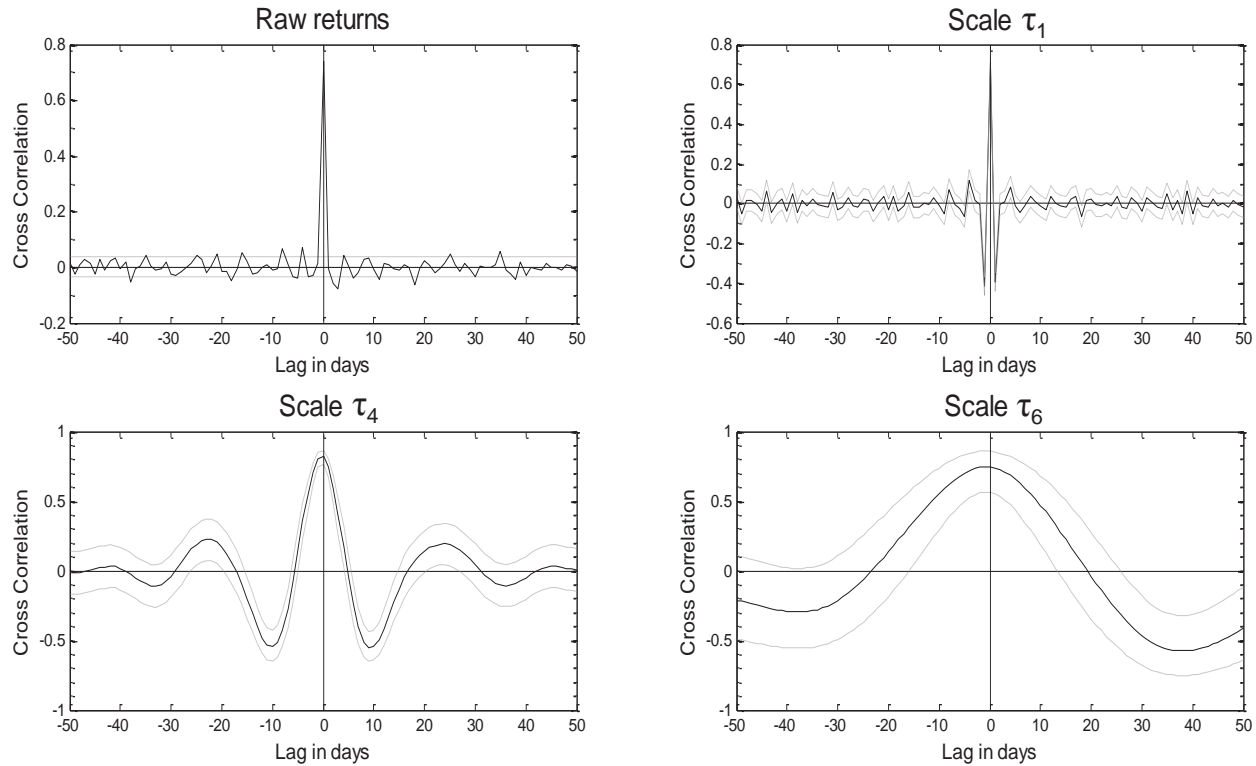

Notes: See notes for Figure 4. 


\section{Figure 9}

Cross-correlation between the Return Series of CAC40 and FTSE100
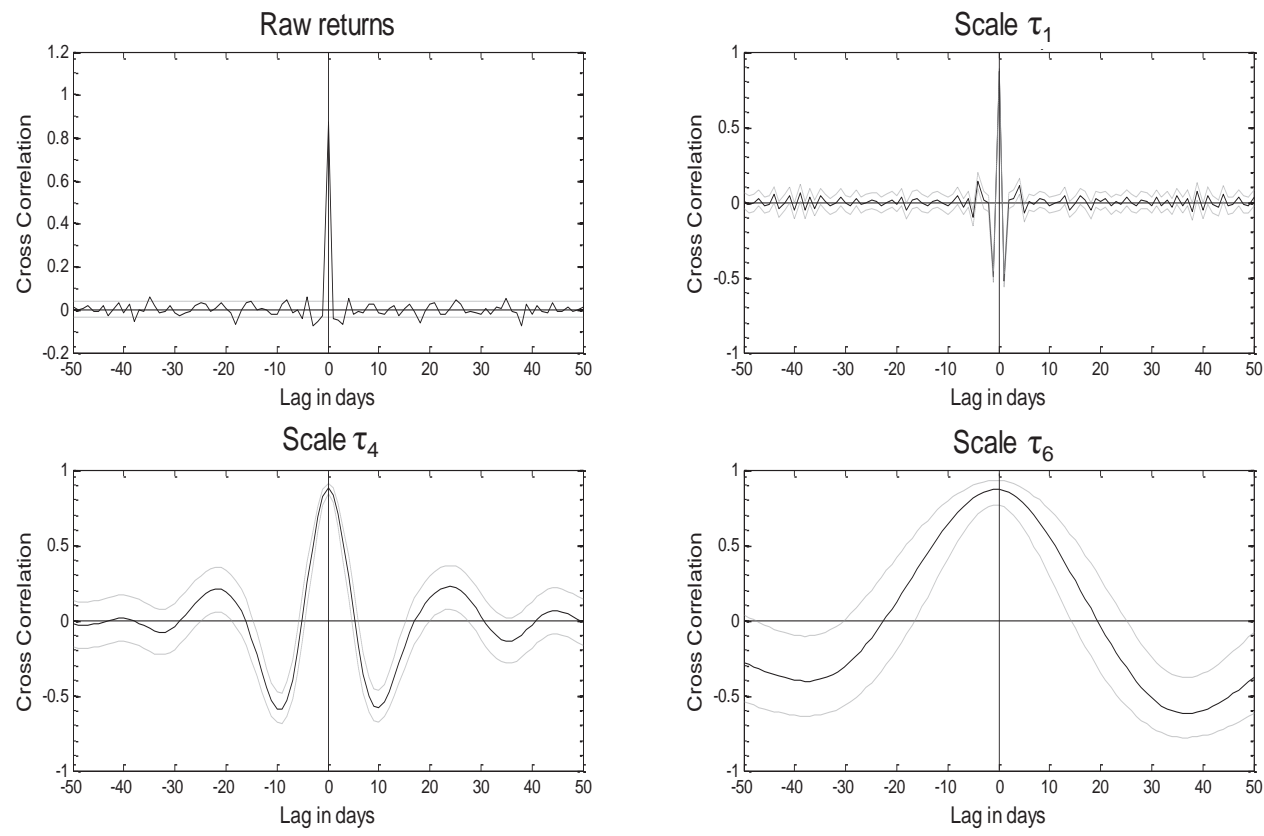

Notes: See notes for Figure 4.

For the raw (daily) return dynamics, the cross-correlation at lag zero is the largest and statistically significant for all stock indices pairs. We note that only a few crosscorrelation estimates for non-zero lags are statistically significant, indicating that stock return dynamics (caused by shocks, due to sporadic events, changes in market sentiment, or new information in the market) are well time-synchronized across the investigated stock markets.

At scale $\tau_{1}$, corresponding to 2 to 4 days return dynamics in the stock markets, the greatest cross-correlation is estimated for time-aligned stock indices' return series, indicating that stock return dynamics are well time-synchronized across the investigated stock markets at this scale. Only cross-correlations with the time shift of $\pi=1$ and $\pi=-1$ are significantly different from zero, while others are not ${ }^{14}$ (the $95 \%$ confidence intervals around the cross-correlation estimates are illustrated in Figures 3-8).

14 Cross-correlation estimates at this time shift are significantly negative. This is because at the interval of scale $\tau_{1}$ (2-4 days), there are often diverse movements in stock markets. For example, in one day (or in two consecutive days) the stock market returns may increase, whereas the remaining days in the time interval of the time scale the returns may decrease. If two stock markets usually move in the same direction, then shifting one time series of stock market returns $(\pi=1$ or $\pi=-1)$ can produce negative cross-correlations, even if the contemporaneous cross-correlation (i.e., comovement) is highly positive. 
At scale $\tau_{4}$ (corresponding to 16-32 day return dynamics), the highest cross-correlation between stock market returns is observed at lag zero. It may take a longer time (i.e., not intraday), however, for return innovations to transmit between the stock markets. Therefore, more cross-correlations estimated at non-zero lags are significantly different than zero.

At scale $\tau_{6}$, corresponding to return dynamics over a 64 to 128 day horizon, we find that the dynamics of the DAX and CAC40 returns are the most time-synchronized of all stock indices pairs. The highest cross-correlation between the two stock indices is achieved at lag zero. ATX return dynamics at this scale is the least time-synchronized with the other stock indices' returns dynamics. The highest cross-correlation estimates were found at the DAX leading the ATX for 4 days; the CAC40 leading the ATX for 3 days; and the FTSE100 leading the ATX for 5 days. This indicates that spillovers usually occur from the larger European stock markets to the Austrian stock market. The FTSE100 return dynamics mostly precedes not only the ATX (by 5 days), but also the DAX and CAC40 return dynamics (by 1 day), indicating spillovers at this time scale (investment horizon) from the UK to the German and French stock markets.

\section{Conclusion}

In this paper, we have studied multiscale interdependence of stock market returns in Austria, Germany, France, and the United Kingdom during the period April 1, 1997 to May 12, 2010. We found that financial market crises had a significant impact on the volatility of stock market returns. The global financial crisis of 2007-2008 had the greatest and the most durable impact.

After proving that daily return series are stationary, the MODWT energy additive decomposition was used to find that most energy (volatility) of stock indices returns during the observed period were captured by scale $\tau_{1}$ (corresponding to a 2-4 day horizon dynamics) and scale $\tau_{2}$ (corresponding to a 4-8 day horizon dynamics) stock market returns decompositions.

The wavelet cross-correlation estimator was used to analyze comovement and spillover transmission between stock market indices on a scale-by-scale basis. The main findings of the cross-correlation lead/lag analysis are: i) Comovement between stock market returns is a scale-dependent phenomena; ii) There is strong comovement between stock market returns of Germany, France, and the UK at all scales, whereas the Austrian stock market is less connected to the three biggest stock markets in Europe; iii) Stock market return dynamics seem to be well time-synchronized at daily (raw returns), lower (scale $\tau_{1}$ and $\tau_{2}$ ), and mid scales (scales $\tau_{4}$ ); iv) At the highest investigated scale, $\tau_{6}$, corresponding to return dynamics over a 64 to 128 day horizon, we found that the dynamics of the DAX and CAC40 returns are the best time-synchronized of all stock indices pairs, whereas ATX return dynamics at this scale is the least time-synchronized with the other stock indices' return dynamics. The FTSE100 returns innovations at this scale precede return innovations of all other stock indices. 


\section{References}

Bae, K. H., Karolyi. A. G., Stulz, R. M. (2003), "A New Approach to Measuring Financial Contagion." The Review of Financial Studies, Vol 16, No. 13, pp. 717-763.

Boudoukh, J., Richardson, M., Whitelaw, R. F. (2008), "The Myth of Long-horizon Predictability." Review of Financial Studies, Vol. 21, No. 4, pp. 1577-1605.

Cardinali, A. (2009), "A Generalized Multiscale Analysis of the Predictive Content of Eurodollar Implied Volatilities." International Journal of Theoretical and Applied Finance, Vol. 12, No. 1, pp. 1-18.

Cornish, R. C., Bretherton, C. S., Percival, D. B. (2006), "Maximal Overlap Discreete Wavelet Statistical Analysis with Application to Atmospheric Turbulence." Boundary-Layer Meteorology, Vol. 119, No. 2, pp. 339-374.

Craigmile, F. P., Percival, D.B. (2002), "Wavelet-Based Trend Detection and Estimation." in: El-Shaarawi, A., Piegorsch, W. W. eds, Entry in the Encyclopedia of Environmetrics. Chichester, UK: John Wiley \& Sons, pp. 2334-2338.

Craigmile, P. F., Percival, D.B. (2005). "Asymptotic Decorrelation of Between-Scale Wavelet Coefficients." IEEE Transactions on Information Theory, Vol. 51, No. 3, pp. 1039-1048.

Crowley, M. P. (2005), "An Intuitive Guide for Economists." Bank of Finland Research Discussion Paper No. $1 / 2005$.

Daubechies, I. (1992), Ten Lectures on Wavelets. Philadelphia: SIAM.

De Trad, C. H., Fang, Q., Cosic, I. (2001), "Protein Sequence Comparison Based on the Wavelet Transform Approach." PEDS - Protein Engeneering Design \& Selection, Vol. 15, No. 3, pp. 193-203.

Didier, T., Love, I., Martínez Pería, M.S. (2011), "What Explains Comovement in Stock Market Returns during the 2007-2008 Crisis?" International Journal of Finance and Economics. [online first] Available: http://onlinelibrary.wiley.com/doi/10.1002/ijfe.442/pdf.

Égert, B., Kočenda, E. (2010), "Time-varying Synchronization of European Stock Markets." Empirical Economics, Vol. 40, No. 2, pp. 393-407.

Fernandez, V. (2005), "Time Scale Decomposition of Price Transmission in International Markets." Emerging Markets Finance and Trade, Vol. 41, No. 4, pp. 57-90.

Gallegati, M. (2005), "A Wavelet Analysis of MENA Stock Markets." EconWPA Working Paper No. 0512027.

Gallegati, M. (2008), "Wavelet Analysis of Stock Returns and Aggregate Economic Activity." Computational Statistics \& Data Analysis, Vol. 52, No. 6, pp. 3061-3074.

Garcia, R., Tsafack, G. (2009), "Dependence Structure and Extreme Comovements in International Equity and Bond Markets." CIRANO Scientific Paper 2009s-21.

Gençay, R., Selçuk, F., Whitcher, B. (2001a), "Scaling Properties of Foreign Exchange Volatility." Physica A: Statistical Mechanics and its Applications, Vol. 289, No. 1-2, pp. 249-266.

Gençay, R., Selçuk, F., Whitcher, B. (2001b), "Differentiating Intraday Seasonalities through Wavelet Multi-scaling." Physica A, Vol. 289, No. 3-4, pp. 543-556.

Gençay, R., Selçuk, F., Whitcher, B. (2002), "An Introduction to Wavelet and Other Filtering Methods in Finance and Economics." San Diego, Academic Press.

Gençay, R., Selçuk, F., Whitcher, B. (2003), "Systematic Risk and Timescales." Quantitative Finance, Vol. 3, No. 2, pp. 108-116.

Gençay, R., Selçuk, F., Whitcher, B. (2005), "Multiscale Systematic Risk.“ Journal of International Money and Finance, Vol. 24, No. 1, pp. 55-70.

Gerrits, R. J., Yuce, A. (1999), "Short- and Long-term Links among European and US Stock Markets." Applied Financial Economics, Vol. 9, No. 1, pp. 1-9.

Gilmore, G. C., McManus, G. M. (2002), "International Portfolio Diversification: US and Central European Equity Markets. Emerging Markets Review, Vol. 3, No. 1, pp. 69-83. 
Grubel, H. (1968), "Internationaly Diversified Portfolios: Welfare Gains and Capital Flows." American Economic Review, Vol. 58, No. 5, pp. 1299-1314.

Harris, F. R., Pisedtasalasai, A. (2006), "Return and Volatility Spillovers between Large and Small Stocks in the UK", Journal of Business Finance and Accounting, Vol.33, No. 9-10, pp. 1556-1571.

Henry, O. T. (2002), "Long Memory in Stock Returns: Some International Evidence“, Applied Financial Economics, Vol. 12, No. 10, pp. 725-729.

Hudson, I. L., Keatley, M. R., Kang, I. (2010), "Wavelet Characterization of Eucalypt Flowering and the Influence of Climate." Environmental and Ecological Statistics. Available: http://www.springerlink. com/content/7u6l243812k42446.

In, F., Kim, S. (2006), "The Hedge Ratio and the Empirical Relationship between the Stock and Futures Markets: A New Approach Using Wavelet Analysis." Journal of Business, Vol. 79, No. 2, pp. 799-820.

In, F., Kim, S., Marisetty, V., Faff, R. (2008), "Analyzing the Performance of Managed Funds Using the Wavelet Multiscaling Method." Review of Quantitative Finance and Accounting, Vol. 31, No. 1, pp. 55-70.

Kim, S., In, F. (2005), "The Relationship between Stock Returns and Inflation: New Evidence from Wavelet Analysis." Journal of Empirical Finance, Vol. 12, No. 3, pp. 435-444.

Kim, S., In, F. (2007), "On the Relationship between Changes in Stock Prices and Bond Yields in the G7 Countries: Wavelet Analysis." Journal of International Financial Markets, Institutions and Money, Vol. 17, No. 2, pp. 167-179.

Koedijk, K., Campbell, A. J. R., Kofman, P. (2002), "Increased Correlation in Bear Markets." Financial Analysts Journal, Vol. 58, No.1, pp. 87-94.

Lee, H. S. (2004), "Price and Volatility Spillovers in Stock Markets: A Wavelet Analysis." Applied Economics Letters, Vol. 11, No. 3, pp.197-201.

Ling, X., Dhesi, G. (2010), "Volatility Spillover and Time-varying Conditional correlation between the European and US Stock Markets." Global Economy and Finance Journal, Vol. 3, No. 2, pp. $148-164$.

Longin, F., Solnik, B. (1995), "Is the Correlation in International Equity Returns Constant:1960-1990? " Journal of International Money and Finance, Vol. 14, No. 1, pp. 3-26.

Malkiel, B. G. (2003), A Random Walk Down Wall Street. New York: Norton.

Mallat, S. (2009), A Wavelet Tour of Signal Processing. Third edition: The Sparse Way. Oxford: Elsevier.

Mallat, S. G., Zhang, Z. (1993), "Matching Pursuits with Time-frequency Dictionaries." IEEE Transactions of Signal Processing, Vol. 41, No. 12, pp. 3397-3415.

Malliaris, A. G., Urrutia, J. L. (1992), "The International Crash of October 1987: Causality Tests." Journal of Financial and Quantitative Analysis, Vol. 27, No. 3, pp. 353-364.

Markowitz, H. (1952), "Portfolio Selection." Journal of Finance, Vol. 7, No. 1, pp. 77-91.

Mazin, A. M. A. J., Hatemi J. A., Irandoust, M. (2010), "Modeling Time-Varying Volatility and Expected Returns: Evidence from the GCC and MENA Regions." Emerging markets Finance and Trade, Vol. 46, No. 5, pp. 39-47.

Patev, P, Kanaryan, N., Lyroudi, K. (2006), "Stock Market Crises and Portfolio Diversification in Central and Eastern Europe." Managerial Finance, Vol. 32, No. 5, pp. 415-432.

Percival, D. B. (1995), "On the Estimation of the Wavelet Variance. Biometrika, Vol. 82, No. 3 , pp. 619-631.

Percival, D. B., Mojfeld, H. O. (1997), "Analysis of Subtidal Coastal Sea Level Fluctuations Using Wavelets." Journal of the American Statistical Association, Vol. 92, No. 439, pp. 868-880.

Pinho, C., Madaleno, M. (2009), "Time Frequency Effects on Market Indices: World Comovements." Paper presented at Paris December 2009 Finance International Meeting AFFI - EUROFIDAI. 
Ramsey, J. (1999), "Regression over Timescale Decompositions: A Sampling Analysis of Distributional Properties." Economic Systems Research, Vol. 11, No. 2, pp. 163-183.

Ranta, M. (2010), "Wavelet Multiresolution Analysis of Financial Time Series." Acta Wasaensia Paper No. 223.

Savva, C. S., Aslanidis, N. (2010), "Stock Market Integration between New EU Member States and the Eurozone." Empirical Economics, Vol. 39, No. 2, pp. 337-351.

Schwender, A. (2010), "The Estimation of Financial Markets by Means of Regime-switching Model." Dissertation. University of St. Gallen.

Serroukh, A, Walden, A. T., Percival, D. B. (2000), "Statistical Properties and Uses of the Wavelet Variance Estimator for the Scale Analysis of Time Series." Journal of the American Statistical Association, Vol. 95, No. 449, pp. 184-196.

Tse, Y. K., Tsui, A. K. (2002), "A Multivariate Generalized Autoregressive Conditional Heteroscedasticity Model with Time-Varying Correlations." Journal of Business and Economic Statistics, Vol. 20, No. 3, pp. 351-362.

Turbelin, G., Ngae, P., Grignon, M. (2009), "Wavelet Cross-correlation Analysis of Wind Speed Series Generated by ANN Based Models." Renewable Energy, Vol. 34, No. 4, pp. 1024-1032.

Vuorenmaa, T. A. (2006), "A Wavelet Analysis of Scaling Laws and Long-memory in Stock Market Volatility." Bank of Finland Research Discussion Paper 27.

Zhou, J. (2011), "Multiscale Analysis of International Linkages of REIT Returns and Volatilities." Journal of Real Estate Financial Economics. [online first]. Available: http://www.springerlink.com/ content/33v342432q29j835. 